\title{
Economics of Co-firing Coal and Biomass: An Application to Western Canada
}

\author{
Craig M. T. Johnston ${ }^{\mathrm{a}}$ \\ G Cornelis van Kooten ${ }^{\mathrm{b}}$ \\ ${ }^{\mathrm{a} D e p a r t m e n t ~ o f ~ F o r e s t ~ a n d ~ W i l d l i f e ~ E c o l o g y, ~ U n i v e r s i t y ~ o f ~ W i s c o n s i n-M a d i s o n, ~ U S A . ~}$ \\ ${ }^{\mathrm{b}}$ Department of Economics, University of Victoria, Canada.
}

\begin{abstract}
:
Co-firing biomass and coal in retrofitted power plants is an efficient means to reduce carbon dioxide emissions in the energy sector. Under IPCC reporting rules, the impacts of energy produced from biomass would not be reported in the energy sector, thereby effectively lowering the emissions intensity of a power plant. In this study, a carbon tax is compared to a feed-in tariff for incentivizing conversion of coal plants to co-fire with biomass. In the application, a model of the Alberta electrical grid with an intertie to British Columbia is linked to a fibre transportation model for these provinces. Results indicate that there is an upper threshold on a carbon tax after which retrofitting of coal plants is less efficient than increasing natural gas generating capacity. This is not the case with a feed-in tariff as it specifically targets biomass energy. Although the optimal generating mix achieved with a carbon tax leads to lower aggregate emissions than the mix achieved using a feed-in tariff, it will result in higher average generating costs. Results indicate that it is optimal for Alberta to retrofit approximately $500 \mathrm{MW}$ of current coal capacity (8.6\%) to co-fire with biomass, although Alberta wood pellet production acts as a constraint on further conversions.
\end{abstract}

Keywords: Climate change, co-firing, biomass energy, mathematical programming, carbon tax, feed-in tariff

JEL categories: Q23, Q42, Q52, Q27,

Acknowledgements: The authors wish to thank financial support from NSERC's Value Chain Optimization Network and SSHRC. 


\section{INTRODUCTION}

Many countries are hoping to transform their energy sectors away from coal power to renewable sources to reduce their carbon dioxide $\left(\mathrm{CO}_{2}\right)$ emissions. One option is to co-fire biomass with coal to reduce the $\mathrm{CO}_{2}$ emissions intensity of coal plants. Co-firing biomass in existing coal-fired power plants is appealing due to the low incremental investment required to retrofit established facilities and because energy produced from biomass is considered to be carbon neutral (IPCC, 2006). Under IPCC reporting rules the impacts of energy produced from biomass would not be reported in the energy sector but in the Agriculture, Forestry and Other Land-Use (AFOLU) sector (previously the LULUCF sector). Carbon emissions from biomass energy are considered carbon neutral since the IPCC Guidelines assume that carbon lost during harvest equals carbon gained through regrowth. Consequently, many coal plants have been or are in the process of being retrofitted to co-fire with biomass (e.g., see IEA, 2009).

Whether biomass burning should be considered carbon neutral is debatable. As argued by Johnston and van Kooten (2014), biomass burning is only carbon neutral if there is no urgency in addressing climate change, in which case the timing of $\mathrm{CO}_{2}$ flux is unimportant. It only matters that over the harvest cycle the same amount of $\mathrm{CO}_{2}$ is removed from the atmosphere by tree growth as was emitted producing electricity. If there is some urgency to address climate change, however, future removals of $\mathrm{CO}_{2}$ from the atmosphere must be considered less important than current emissions, in which case biomass burning can no longer be considered carbon neutral.

The increased demand for biomass energy has resulted in the creation of new wood product markets, primarily in the form of wood pellets. Driven largely by EU policies, global wood pellet production has increased from 1.7 million tonnes (Mt) in 2000 to 15.7 Mt in 2010 
(Lamers et al., 2012), primarily for use in the European market. ${ }^{1}$ Although Europe is also a large producer, there is limited capacity to increase European pellet production. As a result, the wood pellet manufacturing sector in Canada has emerged as a significant supplier, exporting $1.9 \mathrm{Mt}$ representing 90\% of its pellet production to Europe in $2011 .^{2}$ As of 2012, British Columbia (BC) had 1,875,000 tonnes of wood pellet manufacturing capacity, accounting for 65\% of Canadian capacity and production (WPAC, 2012). This sector has traditionally utilized low-cost mill residuals as feedstock, although significant increases in production will require incorporation of more costly fibre from forest operations. As a result of these European incentives, BC exported 840,000 tonnes of wood pellets to the UK and 240,000 to the Netherlands in 2012 (Industry Canada, 2013).

There are numerous risks to expanding or even maintaining exports of pellets from $\mathrm{BC}$ to Europe, including potential changes in European energy policies, the rapid rise of exports from lower-cost competitors and relatively high shipping costs. It is logical therefore to examine potential new markets as a hedge against too large an exposure to the European market, especially considering the high degree of policy risk associated with pellet exports to Europe. A logical market may be developing close to home.

Under the Copenhagen Accord, Canada agreed to reduce its greenhouse gas emissions by 17\% from 2005 levels by 2020. Currently, coal-fired electricity generation in Canada is

\footnotetext{
${ }^{1}$ European countries have agreed on a binding target to achieve a 20\% share of renewable energy in total energy consumption by 2020. Co-firing biomass with coal is becoming more common in EU countries, with the Netherlands, the UK and Belgium leading the way. These countries have implemented various incentives for retrofitting coal plants. In the Netherlands, power producers receive a feed-in tariff of €67/MWh under the 2002 MEP (Milieukwaliteit van de Elektriciteits Productie). In the UK, electricity generators are required to obtain $12 \%$ of their energy from renewable sources, including biomass. It uses Renewable Obligation Certificates (ROC) to incentivize retrofitting of coal plants to co-fire biomass; the average price an ROC was €55.9/MWh in 2012. Similarly, Belgium relies on Green Certificates (average price in 2012 of $€ 118 / \mathrm{MWh}$ ) to encourage large-scale retrofitting of coal plants.

${ }^{2}$ http://www.pellet.org/production/production (accessed July 10th, 2013).
} 
responsible for $77 \%$ of the $\mathrm{CO}_{2}$ emissions from the electricity sector, despite generating only $15 \%$ of total production. With this in mind, the Government of Canada (2011), through an amendment to the Canadian Environmental Protection Act (1999), imposed an emissions intensity standard for generating electricity from thermal power plants, although it would initially apply only to new plants and those refurbished because of their age. The standard was set at an emissions intensity level commensurate with that for high-efficiency combined-cycle gas turbines (CCGT), initially determined to be $375 \mathrm{tCO}_{2} / \mathrm{GWh}$ but later raised to $420 \mathrm{tCO} / \mathrm{GWh}$.

The new standard is likely to have its biggest impact on Alberta since Ontario had already mandated the elimination of coal-fired power in 2007, using financial incentives for biomass energy as an additional policy tool. ${ }^{3}$ The Alberta electricity sector will play an important role if Canada is to comply with the Copenhagen Accord, as it has 5795 MW of installed coal-fired capacity, which represents 53\% of its current electricity output. In 2007, Alberta became the first jurisdiction in North America to put a price on carbon; it introduced what amounted to (but was not called) a carbon tax that targeted large industrial emitters. Large emitters are required to reduce their carbon emissions intensity by $12 \%$ or pay a $\$ 15$-per-tonne tax on $\mathrm{CO}_{2}$ emissions. A recent government proposal could see the tax increase to $\$ 40 / \mathrm{tCO}_{2}$ in hopes of mitigating emissions by $28 \%{ }^{4}$ It is estimated that companies currently pay $\$ 1.80 / \mathrm{tCO}_{2}$ and that this would rise to $\$ 16 / \mathrm{tCO}_{2}$ if the tax was increased (Kleiss, 2013). ${ }^{5}$

\footnotetext{
${ }^{3}$ Ontario's The Green Energy and Green Economy Act (2009) subsequently introduced feed-in tariffs for electricity generated from renewable sources, including a subsidy on biomass electricity of 13.0-13.8

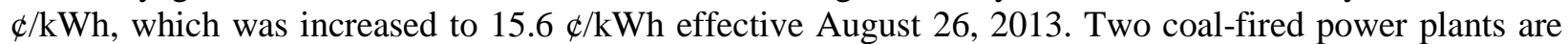
currently undergoing a retrofit to burn biomass, including Nanticoke Generating Station which had been the largest coal plant and one of the largest single sources of emissions in North America. Ontario's capacity to convert biomass residuals to wood pellets is also increasing, with three wood pellet plants under construction and seven more proposed as of 2013 (Canadian Biomass 2013).

${ }^{4}$ Alberta Environment Minister Diana McQueen has proposed a ‘40/40 plan’ to come into effect by 2020; it raises the emissions reduction target to $40 \%$ and increase the carbon price to C $\$ 40$ per tonne.

${ }^{5}$ Unless otherwise indicated, all monetary units are in Canadian currency.
} 
While Alberta and British Columbia (which has no coal plants) have carbon taxes (albeit of different forms), the EU and Ontario rely on feed-in tariffs (FITs) that are implemented as a premium paid to energy produced from biomass (although the EU also employs carbon trading). Unlike a carbon tax, which penalizes emission-intensive technologies across the board, a FIT is designed to encourage investment in renewable energy technologies. As a result, it is expected that reliance on a carbon tax as opposed to a FIT will result in much a different generating mix.

In this paper, we examine optimal investment in generating assets in response to market incentives to reduce $\mathrm{CO}_{2}$ emissions. We use the Alberta energy sector as our case study because of its significant reliance on fossil fuels, especially coal but also natural gas. Additionally, Alberta's proximity to BC allows it to have access to a significant amount of wood pellet manufacturing capacity for co-firing biomass and coal. Indeed, this may provide an opportunity for $\mathrm{BC}$ to expand its market while reducing its exposure to the risk of changes in foreign energy policies. In response to increasing demand for climate change mitigation while providing reasonably priced electricity, co-firing may be beneficial for both provinces. The objectives of the current research are therefore (1) to examine the impact of different market incentives for encouraging the co-firing of biomass with coal; (2) to investigate the potential of reducing $\mathrm{CO}_{2}$ emissions through co-firing biomass with coal; and (3) to determine the feasibility of marketing BC wood pellets in Alberta.

\section{CARBON TAX VERSUS FEED-IN TARIFF}

In this section, we examine how carbon taxes and feed-in tariffs differentially affect the generating mix. Consider Figure 1 where the 2012 hourly Alberta load is depicted in panel (a). By sorting the hourly load in descending order, we derive the 2012 load-duration curve as shown in panel (b). The minimum load is referred to as the base load and is generally met with base- 
load power plants that rarely need to vary output. Nuclear, coal and closed-cycle gas turbine (CCGT) assets constitute the main types of base-load plants.

One can determine the generating mix for a particular grid using the load duration curve and screening curves, which provide the average capacity costs of a specific generating technology. A screening curve plots the annual revenue requirement (variable plus annualized fixed cost component) to retain a generator as a function of the generator's capacity factor, defined as the ratio of a power plant's actual output over a year to its potential output (capacity multiplied by 8760 hours in a year). Screening curves are used to compare generation costs among generating assets by taking into account fixed cost, variable cost and load duration (Stoft, 2002, pp.34-36). Graphically, time (in hours) is plotted along the horizontal axis and cost along the vertical axis. Total cost is comprised of the initial capital expense, which constitutes the vertical intercept of a screening curve, and the variable costs, which represents the slope. The capital expense of installing capacity is the total amortized cost (including interest), while the operating expense constitutes fuel costs (converted from $\$ / \mathrm{MWh}$ to $\$ / \mathrm{kWh}$ ) and annual operating and maintenance costs. Screening curves are assumed to be linear for simplicity - the variable cost is thus assumed to be constant as the capacity factor increases.

In Figure 2, the load duration curve is given in the bottom right part of the diagram with screening curves representing four different technologies provided in the top right diagram. The technologies consist of a typical base-load coal plant, a CCGT base- to mid-load plant, an opencycle gas turbine peak-load plant, and a base-load plant capable of co-firing a fuel mix consisting of $15 \%$ wood pellets and $85 \%$ coal. By dropping vertical lines from the points where two screening curves intersect down to the load duration curve, and then drawing the lines horizontally from the load duration curve to the vertical axis, one can determine the capacities of 
the associated technologies that should be built. This is shown in the diagram on the left in Figure 2. Of course, the slopes and intercepts of the screening curves, and the load duration curve, are not fixed but fluctuate to a greater or lesser degree; the screening curves depend on the cost components discussed above (including importantly fuel costs), while the load duration curve will depend on weather and many other factors that affect demand for electricity from one year to the next. Further, access to reliable fuel sources, such as nearby coal deposits, varies from one region to another, which leads to varying generation mixes across jurisdictions. Nonetheless, this method of selecting a mix of generating assets provides some rough guidance for investors.

From Figure 2, the base-load coal plant has high capital costs but low operating expenses per hour. To offset the high capital cost, the coal plant must have low operating expenses, so it is necessary to ensure that it operates near capacity - it must maintain a high capacity factor. The peak-load plant has a low capital cost combined with a high operating expense, making a low capacity factor optimal for this asset. The mid-load plant, on the other hand, operates at a capacity factor between that of a base-load coal plant and peaking facility. Finally, based on the screening curves in Figure 2, it is not optimal to co-fire biomass with coal as the operating expense is currently not low enough to offset the initial capital cost at any capacity factor.

Without government policy, co-firing biomass and coal may not be considered as part of an optimal generating mix. However, two policies can be implemented for encouraging the cofiring of biomass and coal for energy production, namely, a tax on carbon and a feed-in tariff on electricity produced from biomass. We compare these two policy instruments.

The impact of a carbon tax or FIT on the generating mix can be analysed using loadduration and screening curves. Figure 3 depicts the situation where a carbon $\operatorname{tax}\left(\$ / \mathrm{tCO}_{2}\right)$ penalizes high emission-intensive technologies. Although the capital expenditure required for 
each technology is unchanged, the tax will affect the operating costs of fossil fuel technologies, causing the slopes of their screening curves to become steeper. The greater are a technology's $\mathrm{CO}_{2}$ emissions per unit of output, the greater is the increase in operating expenses. A summary of the $\mathrm{CO}_{2}$-emissions intensities of various technologies is provided in Table 2.

All generating assets depicted in Figure 3 experience an increase in hourly operating expense as a result of a tax on carbon emissions, but coal in Alberta has an emissions intensity of $936 \mathrm{~kg} \mathrm{CO} 2$ per MWh, which is higher than that of other fossil-fuel technologies (see Table 2). Thus, the slope of coal's screening curve is impacted the most. The CCGT power plant has the lowest emissions intensity (420 kg CO 2 per MWh), so the slope of its screening curve is affected to a lesser extent. Peak-load gas plants have emissions intensities somewhere between coal and CCGT, while the emissions intensity of co-firing depends on the proportion of biomass included in the fuel mix and the assumption that biomass burning emits zero $\mathrm{CO}_{2}$. Co-firing biomass with coal at a $15 \%$ rate will result in an operating expense (slope of the screening curve) that is not as steep as coal, possibly allowing co-firing to become cost effective at high capacity factors.

As indicated in Figure 3, with a carbon tax it is optimal to retrofit coal plants to co-fire with biomass. The intercept on the vertical axis representing the fixed cost is unchanged from Figure 2, but the carbon tax reduces the effective slope - the variable cost - of operating a plant that co-fires biomass with coal because of the reduced emissions intensity of such a plant relative to a coal-only power plant. That is, co-firing biomass at $15 \%$ is able to offset the high initial capital expense with relatively lower hourly operating costs (compared to coal alone), making it attractive to include some co-firing capacity in the generating mix. Further, relative to the mix in Figure 2, the carbon tax reduces peak-load gas capacity due to its relatively high emissions intensity, but increases base- and mid-load CCGT capacity at the expense of reduced coal 
capacity because gas emits less $\mathrm{CO}_{2}$ per MWh than coal. Finally, while a carbon tax can be used to encourage investments in co-firing, it is unclear from Figures 2 and 3 whether a carbon tax will be sufficiently high enough to even bring about significant co-firing capacity.

In contrast to a carbon tax, a FIT specifically targets investment in renewable energy technologies such as biomass power production. By subsidizing electricity generated on a perkWh basis, a feed-in tariff lowers the variable operating expense - pivots the screening curve downwards as the slope flattens, in the same way that the carbon tax flattens the screening curve. Unlike a carbon tax, however, the FIT targets only renewable generating capacity, but often in a way that favors one renewable over another while leaving the screening curves of fossil fuel generators unchanged. With a feed-in tariff, one expects coal capacity to be driven out in favour of co-firing, while peak-load and CCGT gas plant capacities are unaffected. The optimal amount of co-firing capacity to install is expected to rise with increases in the FIT for biomass.

To examine the impacts of an emissions intensity mandate and carbon taxes versus feedin tariffs we consider the Alberta electricity grid. The objective of the Alberta Electric System Operator is continuously to balance the province's demand for electricity (or load) and power production at lowest possible cost. The forgoing analysis used screening curves to indicate how decision makers might choose the mix of generating capacities under various incentives, including carbon taxes and feed-in tariffs. Other considerations such as the rates at which generating assets can change output (ramping rates), access to electricity from other jurisdictions via transmission interties, and various technical and engineering constraints also come into play. To model the choice of generating mix and take account of these factors, as well as supply of wood pellets, we employ a numerical mathematical programming model that is described in the next section. 


\section{ALBERTA ELECTRICAL GRID MODEL}

We extend a mathematical programming model of the Alberta electricity grid developed by van Kooten, Johnston and Wong (2013) by integrating a transportation model of wood pellets produced at various locations in British Columbia and Alberta. Each individual coal-fired generating unit in Alberta is modeled, with the decision maker able to retrofit each generator to burn biomass if optimal. The model is first used to examine solely the impact of the emissionsintensity mandate, and then to compare the effects of different levels of a carbon tax versus different levels of a feed-in tariff, on the optimal generating mix and $\mathrm{CO}_{2}$ emissions.

Alberta's power system is completely deregulated, with the Alberta Electric System Operator (AESO) using prices and knowledge about load and power output to allocate generation across assets. Although private firms make decisions on the basis of prices, the model we develop assumes the AESO decides on the decommissioning of extant fossil-fuel generation assets, investment in new natural gas assets, and retrofitting of current coal-fired generating capacity to co-fire biomass and coal. Some trade in electricity between Alberta and British Columbia is also permitted, although it is constrained by intertie transmission constraints and dictated on an hourly basis by price differentials between the provinces.

The AESO is thus assumed to maximize annual profit $\Pi$ (\$) subject to load, trade and engineering constraints. The profit function can be written as:

$$
\text { (1) } \begin{aligned}
\Pi= & \sum_{t=1}^{T}\left[P_{A, t} L_{t}-\sum_{i}\left(O M_{i}+b_{i}+\tau \varphi_{i}\right) Q_{i, t}+F \sum_{i} \gamma_{i} Q_{i, t}\right] \\
& +\sum_{t=1}^{T}\left[\left(P_{A, t}-P_{B C, t}-\delta\right) M_{t}+\left(P_{B C, t}-P_{A, t}-\delta\right) X_{t}\right] \\
& -\sum_{r} \sum_{i}\left(\alpha D_{r, i}+P_{w, r}\right) W_{r, i}-\sum_{i}\left(a_{i}-d_{i}\right) \Delta C_{i},
\end{aligned}
$$

where $i \in I=\{$ CCGT, peak gas, coal, retrofitted coal $\}$ refers to the generation source and $T$ is 
the number of hours in a year (8760). ${ }^{6}$ The first term in (1) is the revenue associated with power generation where $L_{t}$ refers to the demand or load that has to be met in hour $t(\mathrm{MW})$; $P_{A, t}$ is the Alberta electricity price in hour $t(\$ / \mathrm{MWh}) ; Q_{i, t}$ is the electricity produced by generator $i$ in hour $t$ (MW); $O M_{i}$ refers to the hourly operating and maintenance cost of generator $i(\$ / \mathrm{MWh})$; and $b_{i}$ refers to the variable fuel cost of producing electricity using generator $i$ (\$/MWh), which is assumed to be constant for all levels of output.

We assume constant fuel prices because we lack data on how fuel prices change with output, plus the fact that much coal and natural gas is sold under long-term contracts, which implies that prices are fixed for long periods. Further, the price of fuel to a co-firing facility is implicitly assumed to be a weighted price of the coal and biomass costs. As to the market incentives for reducing $\mathrm{CO}_{2}$ emissions, $\tau$ represents the carbon tax (\$ per $\mathrm{tCO}_{2}$ ) and $\varphi_{i}$ is the emissions intensity ( $\mathrm{kg} \mathrm{CO}$ emitted per MWh) of generation source i's fuel source, where the emissions intensity for a co-firing facility is adjusted to account for zero-emissions biomass.

Lastly, $F$ refers to the feed-in tariff (\$/MWh) for biomass, which is adjusted by the proportion $\gamma_{i}$ of the electricity produced from biomass in coal-fired generator $i$ that has been converted to co-fire with biomass (with $F=0$ for generators that do not burn biomass).

The second term in (1) represents the costs or revenues associated with the trade of electricity along the Alberta-BC transmission intertie. We let $P_{k, t}$ be the price (\$/MWh) of electricity in province $k(=\{\mathrm{AB}, \mathrm{BC}\})$ in hour $t$; however, while Alberta prices vary hourly, the $\mathrm{BC}$ price is assumed to be fixed because all information on BC prices is proprietary. $M_{t}$ refers to the amount of power imported by Alberta from BC at $t$, while $X_{t}$ is the amount exported from Alberta to $\mathrm{BC} ; \delta$ is the transmission cost $(\$ / \mathrm{MWh})$, which includes the costs of line losses.

\footnotetext{
${ }^{6}$ Each generator within a coal plant is treated separately in the model for reasons related to wood chip availability (see below), while generators using other fuel sources are aggregated according to fuel types.
} 
Wood pellet costs are represented by the third term in (1). $W_{r, i}$ refers to the annual tonnes of wood pellets purchased from pellet producer $r$ (discussed below) destined for co-firing at retrofitted coal generator $i$. $D_{r, i}$ is the distance $(\mathrm{km})$ from pellet producer $r$ to pellet consuming source $i$, multiplied by $\alpha$ which represents the cost of transporting one tonne of wood pellets a distance of one kilometre. $P_{w, r}$ represents the FOB pellet price (\$/tonne) from pellet mill $r$. Specific information on wood pellet prices is presented in section 4.

Finally, the last term in (1) permits the addition or removal of generating assets, where $a_{i}$ and $d_{i}$ refer to the annualized cost of adding or decommissioning assets ( $\left.\$ / \mathrm{MW}\right)$, and $\Delta C_{i}$ is the capacity added or removed. In the case where generators are retrofitted from burning solely coal to burning a mix of coal and biomass, $\left(a_{i}-d_{i}\right)$ represents the annualized retrofitting cost and $\Delta C_{i}$ the amount of coal capacity that is retrofitted.

Objective function (1) is maximized subject to the following constraints:

(2) Demand is met in every hour: $\quad \sum_{i} Q_{t, i}+\left(M_{B C, t}-X_{B C, t}\right) \geq D_{t}, \forall t=1, \ldots, T$

(3) Ramping-up constraint: $\quad Q_{t, i}-Q_{(t-1), i} \leq \frac{C_{i}}{R_{i}}, \forall i, t=2, \ldots, T$

(4) Ramping-down constraint: $\quad Q_{t, i}-Q_{(t-1), i} \geq-\frac{C_{i}}{R_{i}}, \forall i, t=2, \ldots, T$

(5) Generator capacity constraints: $\quad Q_{i, t} \leq C_{i}, \forall t, i$

(6) Import transmission constraint: $\quad M_{t} \leq T R, \forall t=1, \ldots, T$

(7) Export transmission constraint: $\quad X_{t} \leq T R, \forall t=1, \ldots, T$

(8) Non-negativity: $\quad W_{r, i}, Q_{i, t}, M_{t}, X_{t} \geq 0, \forall r, i, t$

$R_{i}$ is the amount of time it takes to ramp production from plant $i$, while the capacity of the 
transmission intertie between the provinces is denoted $T R .^{7}$

The amount of wood pellets (tonnes) required in a given hour $\eta_{i, t}$ to supply a retrofitted coal-biomass power plant must equal the amount of electricity generated (MWh) for a given rate of co-fire divided by the heat content of wood pellets, $\lambda \approx 5 \mathrm{MWh} / \mathrm{t}$ (EIA, 2012):

(9) $\eta_{i, t}=\frac{\gamma_{i} \times Q_{i, t}}{\lambda}, \forall t, i$.

In addition, the pellets delivered to a retrofitted power plant from all sources $r$ during the period under consideration (annually in our model) must be at least that required to produce the called for power:

(10) $\sum_{r} W_{r, i} \geq \sum_{t} \eta_{i, t} \forall i$.

Further, the amount of wood pellets shipped from pellet producing facility $r$ must not exceed the capacity $C_{r}^{W}$ (tonnes) of the plant:

(11) $\sum_{i} W_{r, i} \leq C_{r}^{W} \forall r$

It is assumed that all generators of a given type operate efficiently, with only the output of the marginal generator fluctuating (ramping) up and down as needed. Generators that are not needed are removed, although decommissioning of capacity is assumed to be continuous. Further, the added costs of shutdown and start-up of thermal power plants associated with wind variability are not taken into account. The decision variables in the model are $Q_{i, t,}, \Delta C_{i}$ (which includes the decision to retrofit a coal generator to co-fire with biomass), $M_{t}, X_{t}, \eta_{i, t}$, and $W_{r, i}$, with the latter two pertaining to wood pellets.

\footnotetext{
${ }^{7}$ An added constraint, $X_{t} \times M_{t}=0$, is needed to ensure that exports and imports of electricity do not occur in the same hour. The constraint is ignored because it is satisfied automatically via the second term in the objective function where, in any given hour, prices either trigger imports or exports but not both.
} 


\section{DATA}

In 2012, the Alberta generation mix consisted of 5,795 MW of coal-fired generating capacity, 4164 MW of CCGT capacity, 1500 MW of peak-load natural gas capacity, 900 MW of hydroelectric generation, 409 MW of biomass capacity, and 1123 MW of installed wind generating capacity associated with 490 wind turbines. In addition, Alberta can trade power with British Columbia. The capacity of the existing intertie between Alberta and BC varies with direction, but we simply assume a single transmission capacity constraint of $750 \mathrm{MW}$. BC is dominated by hydroelectricity that accounts for $11,000 \mathrm{MW}$ or $92.4 \%$ of BC's generating capacity and its hydro reservoirs have the capacity to store energy from Alberta.

Coal generating capacity is distributed across 16 coal-fired units in six power plants (Table 1), with an average emissions intensity equal to $936 \mathrm{tCO}_{2} / \mathrm{GWh}$ (Table 2). Coal-fired generating stations in Alberta are optimally located near coal mines, as well as transmission lines connected to load centers. Coal plants within the province differ considerably with respect to location, age, efficiency and capacity. For example, the oldest coal unit in Alberta is Battle River 3, which was completed in 1969 and has an emissions intensity of $931 \mathrm{tCO}_{2} / \mathrm{GWh}$; Keephills 3, on the other hand, came on-line in 2011 and it has an emissions intensity of $676 \mathrm{tCO} / \mathrm{GWh}$ (Table 1). While a power plant's age certainly has an impact on its emissions intensity, so does the quality of coal available as a fuel, the plant's utilization (i.e., its capacity factor), et cetera. Thus, the optimal installed capacity depends not only on fuel costs, but also emission efficiency. Further, when an existing coal plant is retrofitted, the extant age of the plant will affect the expected life of a retrofitted facility and thereby the period over which the retrofit costs can be amortized. Finally, the location of a coal plant relative to a wood pellet producer will be a significant determinant of whether a coal plant chooses to retrofit. Increased hauling costs result 
in increased average generating costs through increased delivered wood pellet costs.

Alberta’s load is characterized by significant weekly and seasonal variation. The average annual load during 2012 was 8203 MW with a maximum of 10,610 MW and a minimum of 6829 MW. Electricity prices for Alberta and BC are used to determine movements along the interties. In 2012, market clearing electricity prices averaged \$90/MWh in Alberta, ranging from a low of $\$ 0$ to a high of $\$ 1,000$. The BC system is not de-regulated so prices are unknown; thus, we assume a fixed BC price of \$75/MWh based on information from contacts with independent power producers and BC Hydro’s expected future costs.

\section{Technical Details}

It is estimated that 234 coal-fired power plants have been retrofitted globally to co-fire with biomass on a commercial basis, with a majority co-firing at rates below 15\% (IEA, 2009). In most cases, plants retrofitted to co-fire on a continual basis do so at rates varying from $5 \%$ to 15\% (IEA, 2012). Indeed, co-firing proportions in conventional coal plants have increased from roughly $1 \%$ to $10 \%$ of energy input to over $20 \%$ in the past decade (IEA, 2009). Recent studies suggest that substitution of coal for biomass can readily be achieved for levels up to 50\%, depending on the co-firing technique (DENA, 2011; Vattenfall, 2011; IRENA, 2013). Direct cofiring with pre-milled wood pellets in pulverized coal-fired boilers allows for greater flexibility in co-fire rates. However, co-firing at high rates may lead to efficiency losses due to fouling and slagging associated with corrosion (IEA, 2009; IRENA, 2012). This could significantly increase operating costs.

As a result, this study examines a range of co-firing rates. In this way, current coal-fired capacity within Alberta can be relied upon with only minor retrofit costs. Co-firing at these rates requires a capital investment for boiler modifications and fuel handling. Information on 
construction and operating costs, $\mathrm{CO}_{2}$ emissions and ramping rates for generators are provided in Table 2. The overnight construction cost of 'retrofit' refers to the incremental investment required to transform an already existing direct feed coal-fired generating station to run on a combination of coal and biomass as a fuel source.

In the analysis, both available hydro- and wind-generated power are subtracted from load in each hour as they are considered 'must run'. Alberta's hydroelectricity primarily consists of run-of-river facilities, while, in the current model, the total number of wind turbines is held fixed. This is done so that we can focus solely on biomass energy while not being concerned about the potential interaction between feed-in subsidies for biomass versus wind.

\section{Wood Pellets}

The wood pellet industry in western Canada is dominated by British Columbia, with minor productive capacity in Alberta. British Columbia is home to approximately 1.9 Mt of wood pellet manufacturing capacity, centred primarily in the central and northern regions of the BC Interior (Table 3). This industry has grown substantially in recent years, with two new manufacturing plants established in 2013 (Merritt and Kamloops). British Columbia is looking to take advantage of this expanding market with two new proposed plants in Northern BC, providing an additional capacity of over 200,000 tonnes per year (Canadian Biomass, 2013).

Wood pellet manufacturing in British Columbia is ideally located in close proximity to sawmill residue supply from lumber manufacturing, as well as increased fibre supply from unmerchantable timber from the mountain pine beetle infestation. Nevertheless, the fuel cost associated with wood pellets to generate power is sensitive to the distance between the power plant and pellet mill. Table 3 provides estimates of the transport costs from pellet producers to coal-fired power plant in Alberta (\$/t). This calculation is based off estimated trucking costs of a 
Super B-train grain truck, which is an 8-axle configuration with two trailers, hauling 44 tonnes of wood pellets. On average, wood pellets from within BC have an estimated transportation cost of \$51/t to an Albertan coal-fired power plant, while sourcing pellets from within Alberta has an average estimated transport cost of $\$ 32 / \mathrm{t}$.

It is assumed that a retrofitted co-firing power plant in Alberta must pay at least as much as what a pellet manufacturer would receive by shipping overseas. Wood pellet prices are provided in Figure 4; prices averaged \$135.88/t (FOB from the Port of Vancouver) in 2012, reaching a high of $\$ 140.25 / \mathrm{t}$ and a low of $\$ 130 / \mathrm{t}$. Since this price includes the shipping cost from the pellet producer in the $\mathrm{BC}$ interior to Vancouver, average shipping costs of $\$ 41.93 / \mathrm{t}$ during this period need to be subtracted, thereby providing an average FOB mill price of $\$ 93.95 / \mathrm{t}$ (Argus Biomass Markets, 2012). Thus, to obtain prices in Alberta, it is necessary to add the cost of transporting pellets from the BC mill to an Alberta power plant (Table 3). The average fuel cost of wood pellets for Albertan coal-fired power plants is approximately $\$ 27.18 / \mathrm{MWh}$.

\section{MODEL RESULTS}

To understand how Alberta's generating mix might respond to policies that aim to achieve these emissions-intensity targets, we employ a carbon tax that varies from $\$ 0$ to $\$ 200$ per $\mathrm{tCO}_{2}$. This policy is compared to the use of a feed-in tariff that varies from $\$ 0$ to $\$ 120$ per MWh of biomass energy produced. A feed-in tariff is a more common market incentive to encourage the transition towards biomass energy generation. In essence, we wish to determine the regulatory regimes under which the energy sector in Alberta is able to compete with the EU for British Columbian wood pellets. As well, we examine the different effects a tax and a subsidy have on the optimal generating grid in Alberta, with the ability to co-fire coal with biomass. 


\section{Capacity and Generation}

First, consider the impact of a carbon tax on the optimal generation mix in Alberta. In Table 4, the current generating mix is provided in the first row, while the optimal results under different policy scenarios are provided in the following rows. As indicated in section 2, it appears as though there are lower and upper carbon tax thresholds in which co-firing may be optimal. Further, if the co-firing rate is too low, it will never be optimal to retrofit a coal plant.

In Table 4, the carbon tax drives a majority of the pure-fired coal out of the generating mix, for either a $5 \%$ or $15 \%$ co-fire rate. Under both co-firing rates, coal capacity declines from $5795 \mathrm{MW}$ to $359 \mathrm{MW}$ as the carbon tax increases from $\$ 0$ to $\$ 200$ per $\mathrm{tCO}_{2}$. Regardless of the cofiring rate, as the carbon tax increases to $\$ 200 / \mathrm{tCO}_{2}, 3100 \mathrm{MW}$ of new natural gas capacity is added because it is relatively cheaper to build and operate due to low fuel costs as well as relatively low emissions intensity.

If we were to co-fire at a 5\% rate of biomass as fuel, co-firing would never be the optimal choice under a carbon tax scenario. Due to the small amount of biomass as a percent of total fuel, the reduction in the effective emissions intensity is insignificant. As a result, the benefit of cofiring (avoided carbon taxes) falls below the required retrofit cost, thus never allowing co-firing at $5 \%$ to become the optimal choice.

If we increase the co-fire rate to $15 \%$, it becomes optimal to retrofit up to $3,398 \mathrm{MW}$ of currently installed coal capacity to co-fire with biomass. At a carbon tax of $\$ 50 / \mathrm{tCO}_{2}$, the avoided carbon tax associated with co-firing at $15 \%$ outweighs the retrofit cost to convert a coal plant to use both biomass and coal. In fact, at this level, $800 \mathrm{MW}$ of natural gas peak-load generation is also removed. In addition, average electricity generating costs are \$5.71/MWh lower with the $15 \%$ co-fire scenario than they are for the $5 \%$ scenario, assuming a carbon tax of $\$ 50 / \mathrm{tCO}_{2}$. These savings represent the low retrofit cost required to allow biomass and coal to be 
co-fired in current coal capacity, along with reduced applicable carbon taxes through lower emissions intensities.

When the carbon tax becomes too high, low-emissions natural gas pushes coal electrical generation out of the mix, with no biomass entering whatsoever. Under the $15 \%$ co-firing rate, this appears to happen at a carbon tax somewhere above $\$ 100 / \mathrm{tCO}_{2}$. Although co-firing with biomass allows coal capacity to lower their emissions intensity, it is offset by the substantial carbon payments made at high carbon tax rates. At such rates, there are cost savings in transforming the electrical grid towards lower emitting natural gas.

If a feed-in tariff is used as a financial instrument to encourage currently installed coal capacity to co-fire with biomass, we see a much different picture. First, under both low and high rates of co-firing, a large enough feed-in tariff is successful at encouraging co-firing capacity to enter the optimal generating grid. As indicated in Table 4, a feed-in tariff of $\$ 60 / \mathrm{MWh}$ is not a sufficient financial incentive to retrofit coal plants to co-fire at 5\%. Meanwhile, if we allow cofiring up to $15 \%$, a similar feed-in tariff encourages 5795MW of coal capacity to be retrofitted. Since the FIT is effectively a subsidy on energy produced from biomass, the greater the co-firing rate, the greater the subsidy received.

Since a carbon tax affects all fossil fuel generating assets, it results in a very high average generating cost $(\$ / \mathrm{MWh})$ to meet the load requirements in Alberta. The most co-firing capacity added while using a carbon tax is under a tax of $50 \$ / \mathrm{tCO} 2$ while co-firing at a $15 \%$ rate. Under this rate, 3398MW of coal capacity is retrofitted to co-fire with biomass, using 890,185 tonnes of wood pellets. The price on carbon will impact a significant amount of the generating sector within Alberta, resulting in an average price of electricity of \$53.36/MWh. Meanwhile, co-firing at a similar $15 \%$ rate with a $\$ 60 / \mathrm{MWh}$ FIT for biomass results in a retrofit of all the currently 
installed coal capacity. Under this scenario, 1.5 Mt of wood pellets are required to fuel the 5795 MW of co-firing capacity, more than under any carbon tax scenario. At this point, the average generating cost to meet Alberta’s load is only $\$ 34.42 / \mathrm{MWh}$. Since a FIT only targets biomass specifically, it incentivizes a greater amount of co-firing capacity, at a much lower generating cost to Alberta.

\section{Reducing Carbon Dioxide Emissions}

Although a feed-in tariff is more successful at encouraging biomass co-firing in currently installed coal capacity, it is unclear how successful the policy is at reducing carbon dioxide emissions. The reason is that a FIT specifically targets biomass energy production but does not target $\mathrm{CO}_{2}$ emissions per se. Table 5 provides emissions and abatement costs found for optimal generating mixes in Alberta, under various regulatory regimes. Two trends are apparent from the emissions output provided in Table 5. First, a tax on carbon in the electricity generating sector leads to lower optimal $\mathrm{CO}_{2}$ emissions than those found when relying on a feed-in tariff on biomass electricity production. The lowest level of $\mathrm{CO}_{2}$ emissions under a carbon tax is a significant 20 Mt lower than that under a feed-in tariff. Indeed, there is virtually no realistic combination in which a FIT for biomass results in lower emissions from the Alberta electricity sector than relying on a carbon tax. FITs of $\$ 90$ and $\$ 120$ per MWh do little because co-firing capacity is constrained by current coal capacity; instead, it would be necessary to construct new biomass capacity, but such new capacity is much more expensive than relying on the conversion of current coal plants to co-fire with wood pellets. Even if this were not the case, current wood pellet manufacturing capacity will inevitably be maxed out.

The second trend, which can be identified from Table 5, is a tax on carbon emissions is more cost effective than a feed-in tariff on biomass in reducing $\mathrm{CO}_{2}$ emissions. Consider a co- 
fire rate of $15 \%$, a carbon tax of $\$ 50$ per $\mathrm{tCO}_{2}$ results in $42.6 \mathrm{Mt}$ of emissions - costing $\$ 253.06$ per avoided $\mathrm{tCO}_{2}$. Meanwhile, a feed-in tariff of \$120/MWh reduced emissions to only $49.8 \mathrm{Mt}$ of $\mathrm{CO}_{2}$ - costing $\$ 355.37$ per avoided $\mathrm{CO}_{2}$. Since abatement costs increase with the feed-in tariff (and carbon tax for that matter), it is clear that any higher feed-in tariff will inevitably result in a higher abatement cost.

\section{Impact of Canadian Coal-fired Performance Standards}

By 2015, when Canada’s emissions-intensity regulation for new and refurbished coal plants comes into effect, it is expected that seven of Alberta's 16 coal-fired generators will be affected by the new regulations within the first ten years. As identified in bold in Table 6, this constitutes 2024 MW (35\%) of currently installed generating capacity. To examine how this policy will impact Alberta's optimal generating mix, as well as the potential for relying on cofiring as a compliance strategy, this scenario has been integrated in the numerical model outlined in Section 3. The current emissions intensity of these units is $961 \mathrm{tCO}_{2} / \mathrm{GWh}$, or more than double the $420 \mathrm{tCO}_{2} / \mathrm{GWh}$ standard, which implies that the seven units affected by the regulation will either have to co-fire at 56\% or shut down entirely.

Although most co-firing is done at or below 15\%, there are examples of fully converted pulverized coal plants relying on high rates of direct co-fired generation. Unit \#4 of the 'Les Awirs' power plant in Belgium was fully retrofitted to burn biomass for upwards of $100 \%$ of its 80-MW capacity; this was followed, in 2011, with the retrofit of the 200-MW capacity unit \#4 of the 'Rodenhuise' coal plant to burn only biomass. In Denmark, the 250-MW unit \#1 of the 'Amager' facility can now directly co-fire biomass with coal at ratios ranging from zero to 100\%

of boiler capacity. There are now two co-fired, direct feed power plants in Canada: The 4000MW capacity 'Nanticoke' generating station in Ontario is a retrofitted pulverized coal plant that 
recently completed test runs with biomass generating up to $100 \%$ of the plant's capacity. Ontario’s 230-MW capacity ‘Atikokan’ power plant recently completed tests using wood pellets to generate as much as $100 \%$ of the plant's power capacity. Atikokan retrofitted to co-fire high rates of biomass at a cost of $\$ 200$ million, or $\$ 870 / \mathrm{MW}$.

Despite this, there is little experience co-firing at high rates over a significant period of time. There are many uncertainties regarding high rates of co-firing including fouling and slagging associated with corrosion, as well as issues related to ensuring a long-term supply of biomass. In the current application, we assume that, at a 56\% co-firing (to comply with the new regulations), the retrofit cost would be $\$ 870 / \mathrm{MW}$. Further, annual biomass supply is assumed to be constrained by 2012 wood pellet manufacturing capacities of 1,875,000 and 145,000 tonnes in British Columbia and Alberta, respectively.

Model results are provided in Tables 7 and 8 . From Table 7, the optimal generating mix in Alberta is dependent on whether or not the option to co-fire exists, as well as the regulatory environment in place. The 'initial' scenario highlights the current (2012) generating mix, while other scenarios represent situations where the Alberta generating mix must comply with the new performance standards for new and refurbished coal plants. That is, the scenarios force the seven generating units indicated in Table 6 to retrofit to co-fire to reduce their respective emissions intensity to the performance standard or shut down.

The 'Current' policy scenario in Table 7 represents the case where coal plants in Alberta must meet the emissions-intensity regulation, but no other policies (carbon tax or feed-in tariff) are implemented. It is then optimal for $495 \mathrm{MW}$ of currently installed coal-fired generating capacity to co-fire with biomass. The remaining 1529 MW of coal capacity subject to the performance standard is shut down. Alberta will also require 484,998 tonnes of wood pellets 
manufactured from Alberta and British Columbia.

As indicated in Table 8, the 495 MW of installed co-fired capacity is spread across three generating units: 158MW in H.R. Milner; $61 \mathrm{MW}$ in Sundance 4; and $275 \mathrm{MW}$ in Sundance 5. Although 85,000 tonnes of wood pellets are sourced from within Alberta to fuel these generating units, 400,000 tonnes per year are sourced from British Columbia. Due to its proximity, Alberta requires all of the output from the current wood pellet producer in Prince George. As a result, 129,993 tonnes of wood pellets annually are shipped to H.R Milner and 270,077 tonnes annually to Sundance 5. Meanwhile, the remainder of the annual wood pellet demand is sourced from within Alberta. H.R. Milner demands an additional 25,000 tonnes annually is met by the Grand Cache pellet producer, while Sundance 4 exclusively sources its 60,000 annual tonnes of wood pellets from Slave Lake. The average delivered price of wood pellets is $\$ 123.95$, which equates to roughly $\$ 24.79$ per $\mathrm{MWh} .^{8}$

The 'Carbon tax' and 'Feed-in tariff' scenarios indicate how changes in the carbon tax and FIT affect the choice of optimal generating mixes. Unlike when there is no tax or FIT, all of the $2024 \mathrm{MW}$ of coal capacity affected by the regulation is retrofitted to co-fire under whenever the carbon tax is $\$ 50 / \mathrm{tCO}_{2}$ or higher, or the FIT is $\$ 30 / \mathrm{MWh}$ or higher. Unlike with a higher FIT, the remaining optimal coal capacity falls significantly as the carbon tax increases; optimal installed capacity falls from $3771 \mathrm{MW}$ for a carbon tax of $\$ 50 / \mathrm{tCO}_{2}$ to $357 \mathrm{MW}$ for a tax of $\$ 200 / \mathrm{CO}_{2}$. In contrast, the optimal capacity of coal generation to retain remains at 3771 regardless of the level of the FIT. As a carbon tax punishes emissions regardless of the source, this policy again leads to significantly lower emissions than any feed-in tariff on biomass.

All scenarios with either a carbon tax, or feed-in tariff, require slightly less than $2.0 \mathrm{Mt}$ of wood pellets, generating approximately 10 TWh of electricity from biomass. The optimal wood

\footnotetext{
${ }^{8}$ This calculation is based off 1 tonne of wood pellets produces 4.8-5.2 MW of electricity.
} 
pellet shipments for a FIT of \$30/MWh from biomass are provided in Table 8. Since any of the regulatory environments considered in Table 7 require a co-fire retrofit of all seven affected coal plants, the shipments in Table 8 are consistent with all scenarios. The wood pellet manufacturing sector in Alberta is fully utilized, while 98\% of British Columbia's wood pellet manufacturing capacity is required to fuel plants in Alberta. As a result, 145,000 tonnes of wood pellets are derived from within Alberta, while 1,841,014 tonnes are sourced from British Columbia. In fact, Battle River Unit 4, and Sundance Units 3, 5, and 6, depend solely on British Columbian wood pellets.

Depending on hauling costs, delivered wood pellet prices vary from a low of $\$ 127.86$ per tonne for H.R. Milner to a high of $\$ 147.98 /$ for Sundance Unit 5. Based on optimally determined shipments, the hauling cost for H.R. Milner is $\$ 31.79 /$ t, while the same cost for Sundance Unit 5 is $\$ 51.91 / t$. The average delivered wood pellet price is $\$ 141.05 / t$, or approximately $\$ 28.21$ per MW, when taken across all seven co-firing units.

It is unclear whether a feed-in tariff will be the best choice for Alberta. On one hand, average generating costs using a feed-in tariff of $\$ 30 / \mathrm{MWh}$ are $\$ 8.04$ per MWh higher than if no additional policy was in place ( $\$ 49.21$ vs $\$ 41.17$ ). However, due to the coal-fired regulations, the optimal generating grid in Alberta may result in lower total generating capacity if no additional policy is put in place. In the first ten years of the performance standard implementation, if no additional policy is used, it is optimal for 1529 MW of coal capacity to shut down, while only 495 MW of co-firing capacity is added. This scenario leads to the lowest level of installed generating capacity in Alberta, with the province relying heavily on imports of hydroelectricity from British Columbia over a $750 \mathrm{MW}$ intertie. On the other hand, the use of a feed-in tariff results in an additional $1404 \mathrm{MW}$ of generating capacity than if no further policy were in place. 
This allows for greater electrical independence from British Columbia, driven mainly through 2024 MW of retrofitted co-firing capacity.

\section{CONCLUDING DISCUSSION}

In light of the external costs associated with $\mathrm{CO}_{2}$ emissions, and the favourable treatment of $\mathrm{CO}_{2}$ emissions associated with the use of biomass energy, electrical grids in many jurisdictions are increasingly burning wood pellets with coal in retrofitted power plants to reduce their $\mathrm{CO}_{2}$ emissions. What makes this feature appealing is the low incremental investment required to transform a coal-dominated grid into one that utilizes a combination of coal and biomass. In addition to the low costs of retrofitting coal plants, financial incentives, especially carbon taxes and feed-in tariffs for biomass, have been used to facilitate the transition towards this lower emitting fuel combination. However, a carbon tax will generally lead to a generating mix that relies more on low-emissions natural gas, which the overarching renewable energy policy seeks to avoid.

Feed-in tariffs were perhaps the most popular financial incentive adopted by EU member states in the electricity sector in response to the EU's target of reducing emissions by $20 \%$ from 1990 levels and obtaining 20\% of energy from renewable sources by 2020. In October, 2014 the EU adopted even more aggressive targets to be implemented by 2030: $\mathrm{CO}_{2}$ emissions are to be reduced by $40 \%$ from 1990 levels, targets are to be legally binding on all member states (whereas 2020 targets had varied among states), the share of renewables in the EU's energy mix is to rise to $27 \%$, and energy efficiency improvements of $27 \%$ are to be realized. The burden of the costs is to be shared by taxpayers and, in the case of electricity, by ratepayers, and costs could be potentially be quite high. This is no more evident than in Germany, which currently leads the EU in installed biomass capacity $(7.11 \mathrm{GW})$ but with electricity prices $48 \%$ higher than 
the EU average. Compared to a carbon tax, a feed-in tariff may lead to higher costs of abating $\mathrm{CO}_{2}$, although the majority of EU countries continue to rely on feed-in tariffs or other subsidies to incentivize greater use of bioenergy (as well as solar and wind). The overall impact of these policies remains, for the most part, unknown.

In addition to policies regarding the incentivizing of biomass burning in thermal power plants, commercial co-firing has many challenges. A large barrier is securing a reliable supply of biomass at sufficiently low cost. As transportation costs are a significant driver of the economics behind co-firing, proximity to fibre is a potential barrier. With this in mind, the Alberta-BC case study was used to identify the feasibility of co-firing wood pellets in existing coal plants, as well as the impacts of using a carbon tax or a feed-in tariff to incentivize retrofitting of coal plants. These provinces were used in the case study because Alberta's grid is dominated by coal-fired, base-load power plants, while British Columbia has a significant amount of wood pellet manufacturing capacity. Thus, co-firing wood pellets with coal may be a cost effective strategy for complying with new emission-intensity regulations of $420 \mathrm{tCO}_{2} / \mathrm{GWh}$. Independent of any other policies, our results indicate that it would be optimal to retrofit approximately $500 \mathrm{MW}$ (or 8.6\%) of Alberta's extant coal capacity to co-fire with biomass, although conversion of more generating capacity might be limited by the availability of wood pellets originating in Alberta.

As noted, there has been a significant increase in wood pellet production capacity in recent years due in large part to aggressive $\mathrm{EU} \mathrm{CO}_{2}$-emissions reduction policies. In the last decade, Canada has benefitted from this growing trend by increasing exports overseas, adding value to its forest product sector. With the potential development of domestic demand in Alberta, some of this wood pellet production in BC will likely be reallocated away from the EU. Indeed, our results indicate that, in light of the pending performance standard on coal-fired power plants 
in Canada, as much as 500,000 tonnes of BC wood pellets could be shipped to Alberta. This represents approximately 25\% of 2012 wood pellet shipments from Canada to the EU.

Since wood pellet producers will export to those regions with the highest prices for wood pellets, after shipping and handling costs, the re-allocation of half a million tonnes of BC pellets from the EU to Alberta will likely have an impact on global wood pellet markets. However, the EU has been diversifying its suppliers of wood pellets in recent years, with the U.S., Russia, and parts of Asia and South America increasing shipments to the EU. Combining this with the fact that Canada represented less than $10 \%$ of total wood pellet supply to the EU, the impact on prices is likely to be small. Future research into the origins of wood fiber used to produce pellets, and global wood pellet markets, is required to answer this and other questions. What is clear nonetheless is that rapidly rising demand for biomass energy will have important repercussions for forestry and other sectors, including energy.

\section{REFERENCES}

AESO, 2013. Alberta Electric System Operator. 10 Minute Historical Data for Total Wind Power and Alberta Internal Load. www.aeso.ca/market/17609.html (viewed June 2, 2013)

Argus Biomass Markets, 2012. Argus Biomass Markets: Weekly Biomass Markets, News And Analysis. (Viewed weekly through 2012)

Arctic Energy Alliance, 2009. NWT Community Wood Pellet Study; Supply and Transport Options for Wood Pellets. GWNT Environment and Natural Resources. www.aea.nt.ca (viewed May 16, 2013)

Canadian Biomass, 2013. Wood Pellet Association of Canada 2013 Pellet Map. http://www.canadianbiomassmagazine.ca/images/CBM-pellet-map-2014.pdf (viewed April 23, 2013)

DENA, 2011. Biomass Co-firing in Coal Power Plants. A Contribution to Energy Policy and Climate Change, DENA, Berlin, 2011. http://www.dena.de (viewed June 12, 2013) 
EIA (US Energy Information Administration), 2012. Electricity Market Module; Assumptions to the Annual Energy Outlook 2012. Electricity Market Module; Assumptions to the Annual Energy Outlook 2012. (viewed April 3, 2013).

EIA (US Energy Information Administration), 2013. Annual Energy Outlook, 2013; with Projections to 2040. http://www.eia.gov/forecasts/aeo. (viewed April 3, 2013).

Government of Canada, 2012. Reduction of Carbon Dioxide Emissions from Coal-Fired Generation of Electricity Regulations, Canada Gazette Vol. 145, No. 35 (August 27, 2012).

IEA (International Energy Agency), 2009. Technical Status of Biomass Co-Firing. Bioenergy Task 32. Arnhem, 11 August. Edited by M.F.G. Cremers. http://www.ieabcc.nl (viewed July 14, 2013).

IEA (International Energy Agency), 2012. Co-firing Biomass with Coal: 3rd Workshop. Clean Coal Centre. June 20-21. Groningen, the Netherlands. http://www.ieacoal.org.uk/site/2010/conferences/cofiring? (viewed July 24, 2012).

Industry Canada, 2013. Trade Data Online. www.ic.gc.ca/tdo (viewed April 12, 2013).

IPCC, 2006. Intergovernmental Panel on Climate Change: 2006 IPCC Guidelines for National Greenhouse Gas Inventories. http://www.ipcc-nggip.iges.or.jp/public/2006gl (viewed June 3, 2012).

IRENA, 2012. Biomass for Power Generation, Renewable Energy Technologies: Cost Analysis Series, Volume 1: Power Sector, Issue 1/5, June 2012. http://costing.irena.org (viewed April 18, 2013).

Johnston, C.M.T. and G.C. van Kooten, 2014. Carbon Neutrality of Hardwood and Softwood Biomass: Issues of Temporal Preference. REPA Working Paper 2014-06. Victoria, BC: Department of Economics, University of Victoria.

Kleiss, Karen, 2013. Alberta's carbon tax would more than triple under government's proposal, Edmonton Journal April 8, 2013. http://www.edmontonjournal.com/technology/Alberta+carbon+would+more+than+triple +under+government/8213625/story.html (viewed June 4, 2013).

Lamers, P., M. Junginger, C. Hamelinck, A. Faaij, 2012. Developments in International Solid Biofuel Trade - An Analysis of Volumes, Policies, and Market Factors. Renewable and Sustainable Energy Reviews 16(2012) 3176-3199. 
Stoft, S., 2002. Power System Economics. Designing Markets for Electricity. Piscataway, NJ: IEEE Press and Wiley-Interscience.

van Kooten, G.C., C. Johnston, L. Wong, 2012. Wind versus Nuclear Options for Generating Electricity in a Carbon-Constrained world: Strategizing in an Energy Rich Economy. Amer. J. Agr. Econ. 95(2): 505-511

Vattenfall, 2011. Test Results of the Experimental Program with 4,300 tons of Refined Wood Pellets - Reuter West CHP May-July 2011; Berlin. http://www.vattenfall.com/en/file/2011_Annual_Report.pdf_20332206.pdf (viewed June 15, 2012).

WPAC, 2012. Wood Pellet Association of Canada. Canadian Wood Pellets - An Industry on the Move. CANBIO Annual Conference \& Trade Show. November 27-28, 2012. Vancouver BC. http://www.canbio.ca/upload/documents/van-12-presentations/wood-robert.pdf (viewed July 18, 2013). 
(a)

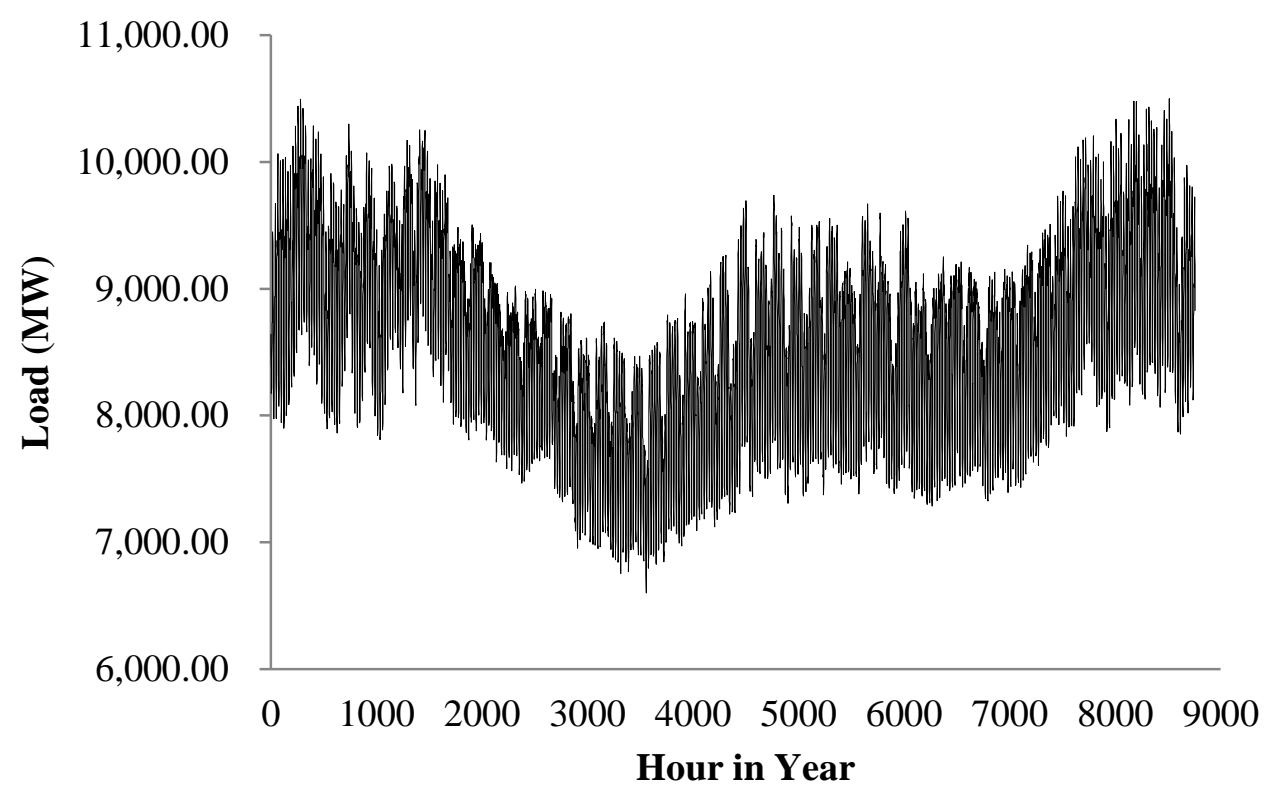

(b)

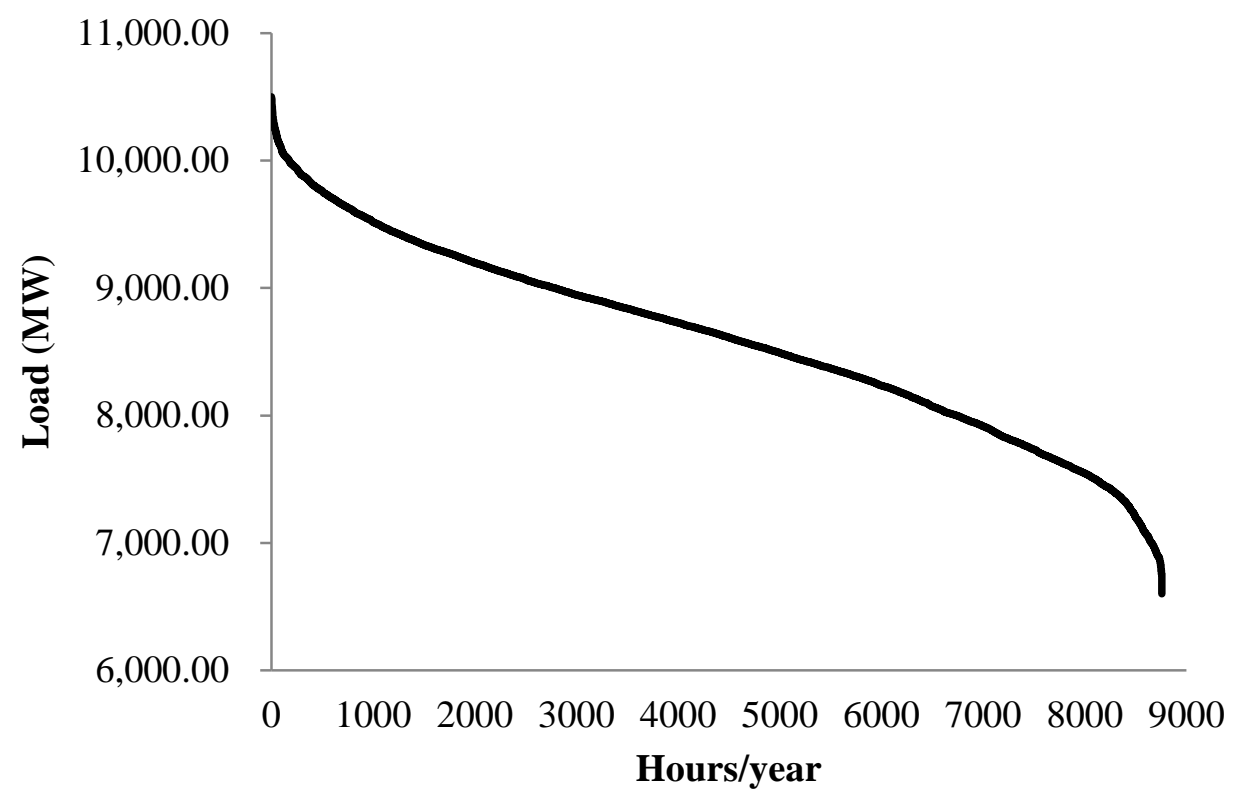

Figure 1: 2012 Alberta load (panel a) and load duration curve (panel b) 


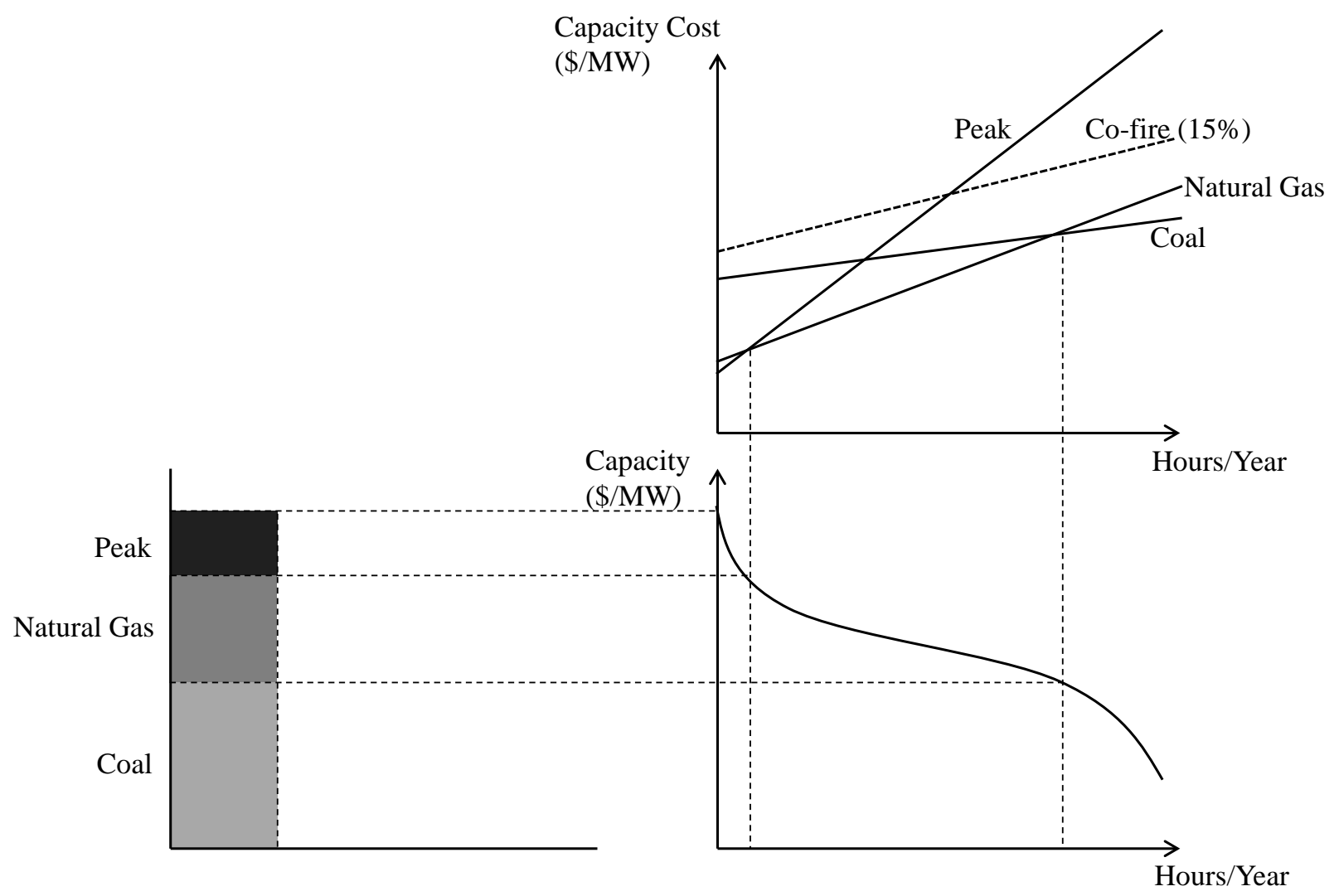

Figure 2: Optimally installed generation capacities based on screening curves and load duration curve: Absent government policy 


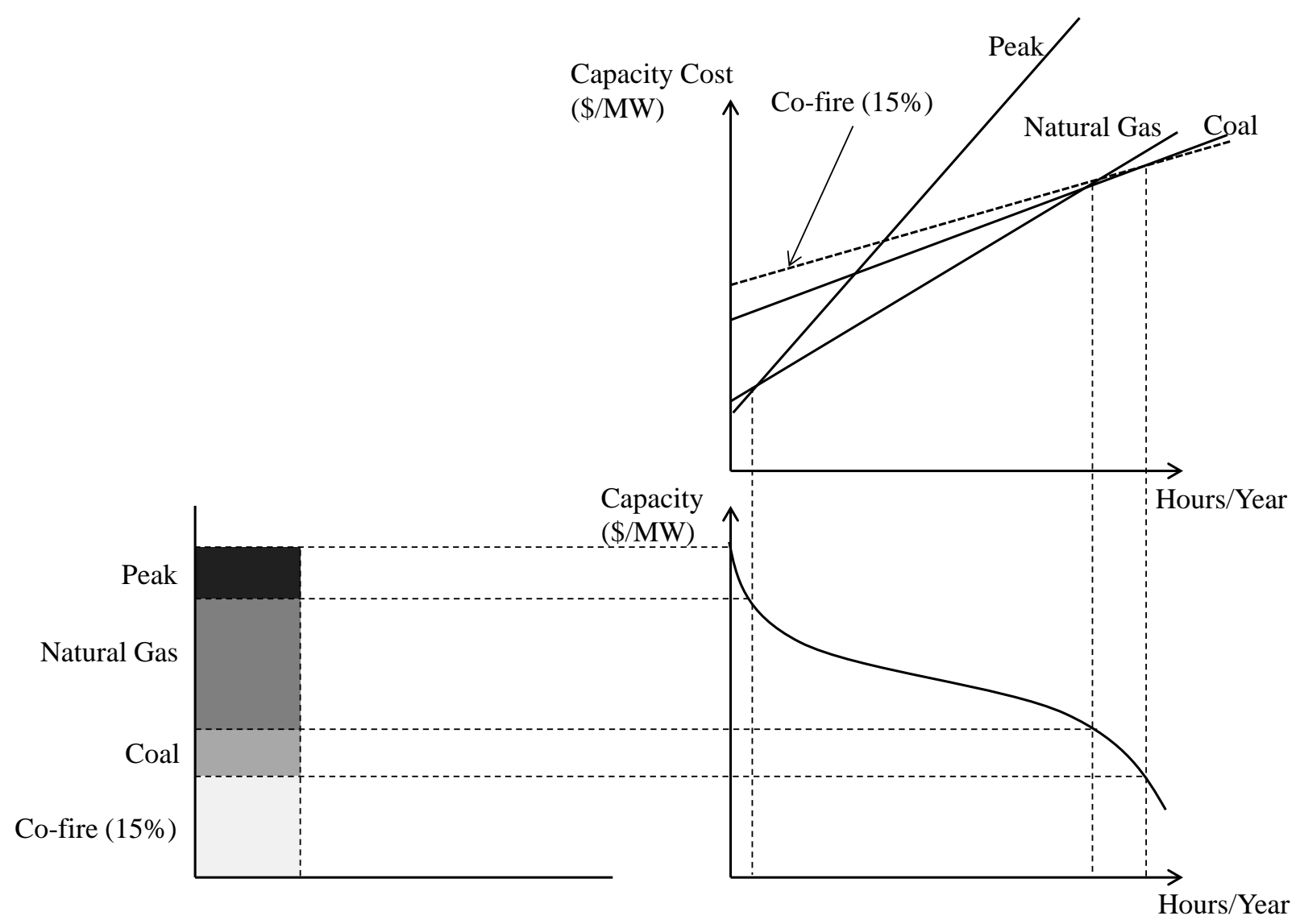

Figure 3: Optimally installed generation capacities based on screening curves and load duration curve: Carbon tax scenario that increases the slopes of screening curves for fossil fuel generators but that of co-firing plants to a lesser extent 


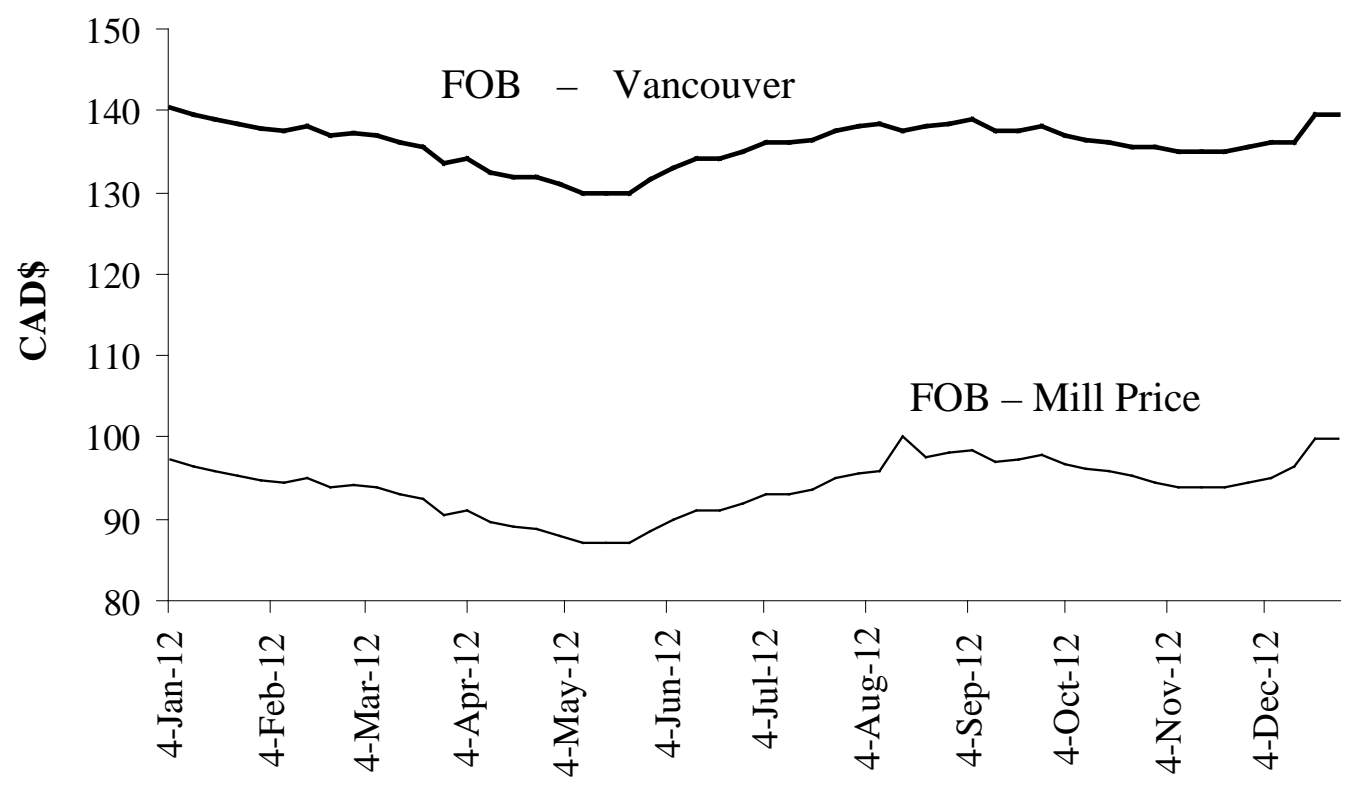

Figure 4: Wood pellet prices (C\$ per tonne), Weekly 2012 Source: Argus Biomass Markets 
Table 1: Installed coal-fired capacity in Alberta, 2012

\begin{tabular}{|c|c|c|c|c|c|}
\hline $\begin{array}{l}\text { Station } \\
\text { Unit }\end{array}$ & $\begin{array}{l}\text { Capacity } \\
\text { (MW) }\end{array}$ & $\begin{array}{l}\text { Completed } \\
\text { (Year) }\end{array}$ & $\begin{array}{r}\mathrm{CO}_{2} \\
(\mathrm{t} / \mathrm{GWh})^{\mathrm{a}} \\
\end{array}$ & $\begin{array}{r}\text { NOx } \\
(\mathrm{t} / \mathrm{GWh})^{\mathrm{a}} \\
\end{array}$ & $\begin{array}{r}\mathrm{SO}_{2} \\
(\mathrm{t} / \mathrm{GWh})^{\mathrm{a}}\end{array}$ \\
\hline \multicolumn{6}{|c|}{ Battle River } \\
\hline 3 & 150 & 1969 & 931 & 1.9 & 5.5 \\
\hline 4 & 150 & 1975 & 882 & 1.8 & 5.4 \\
\hline 5 & 389 & 1981 & 1,176 & 2.4 & 5.0 \\
\hline \multicolumn{6}{|l|}{ Genesee } \\
\hline 1 & 410 & 1989 & 980 & 2.0 & 2.0 \\
\hline 2 & 410 & 1994 & 980 & 2.0 & 2.0 \\
\hline 3 & 495 & 2005 & 676 & 0.7 & 0.9 \\
\hline \multicolumn{6}{|c|}{ HR Milner } \\
\hline 1 & 158 & 1972 & 1,103 & 2.3 & 3.0 \\
\hline \multicolumn{6}{|l|}{ Keephills } \\
\hline 1 & 396 & 1983 & 1,103 & 2.3 & 2.1 \\
\hline 2 & 396 & 1983 & 1,127 & 2.3 & 2.1 \\
\hline 3 & 495 & 2011 & 676 & 0.7 & 0.6 \\
\hline \multicolumn{6}{|c|}{ Sheerness } \\
\hline 1 & 390 & 1986 & 1,127 & 2.3 & 6.4 \\
\hline 2 & 390 & 1990 & 1,127 & 2.3 & 6.4 \\
\hline \multicolumn{6}{|l|}{ Sundance } \\
\hline 3 & 408 & 1976 & 980 & 2.0 & 1.8 \\
\hline 4 & 386 & 1977 & 931 & 1.9 & 1.8 \\
\hline 5 & 386 & 1978 & 833 & 1.7 & 2.0 \\
\hline 6 & 386 & 1980 & 784 & 1.6 & 2.0 \\
\hline
\end{tabular}

${ }^{\mathrm{a}}$ Source: Environment Canada (2013) 
Table 2: Construction and Operating Costs (\$2012), $\mathrm{CO}_{2}$ Emissions, and Ramp Rates of Various Generating Assets

\begin{tabular}{|c|c|c|c|c|c|c|c|}
\hline \multirow[b]{2}{*}{ Asset } & \multirow[b]{2}{*}{$\begin{array}{l}\text { Years } \\
\text { to } \\
\text { build }\end{array}$} & \multicolumn{2}{|c|}{ Construction Costs ${ }^{\mathrm{a}}$} & \multicolumn{2}{|c|}{$\begin{array}{l}\text { Variable Costs } \\
(\$ / \mathrm{MWh})^{\mathrm{a}}\end{array}$} & \multirow[b]{2}{*}{$\begin{array}{c}\text { Emissions } \\
\text { intensity } \\
\left(\mathrm{tCO}_{2} / \mathrm{MWh}\right)\end{array}$} & \multirow[b]{2}{*}{$\begin{array}{c}\text { Ramp rate \% } \\
\text { of capacity } \\
\text { per hour }\end{array}$} \\
\hline & & $\begin{array}{c}\text { Overnight } \\
(\$ / \mathrm{kW})\end{array}$ & $\begin{array}{c}\text { Decommission } \\
\text { as \% of } \\
\text { overnight }\end{array}$ & O\&M & Fuel & & \\
\hline Coal & 4 & 2658.0 & 24.0 & 4.25 & 7.75 & $0.936^{\mathrm{b}}$ & 2.5 \\
\hline Retrofit & 1 & 274.0 & 24.0 & n.a. & n.a. & n.a. & 2.5 \\
\hline Wind & 3 & 1300.0 & n.a. & 0.00 & 0.00 & 0.015 & n.a. \\
\hline Hydro & 4 & 2134.0 & n.a. & 2.55 & 1.01 & 0.009 & n.a. \\
\hline CCGT & 3 & 927.0 & 10.0 & 9.87 & 14.69 & 0.420 & 7.5 \\
\hline OCGT & 2 & 634.0 & 10.0 & 14.70 & 19.56 & 0.600 & 12.5 \\
\hline
\end{tabular}

${ }^{\mathrm{a}}$ EIA, 2012

${ }^{\mathrm{b}}$ Average emissions intensity of coal plants within Alberta as of 2012. Emissions data from Environment Canada

${ }^{\mathrm{c}}$ Estimates based on AESO (2010, p.13) and total system ramp rate of 600 MW per hour 


\section{Table 3: Estimated Cost of Transporting Wood Pellet from Producer to Power Plant (\$/tonne)}

Pellet Producer

\begin{tabular}{|c|c|c|c|c|c|c|c|}
\hline $\begin{array}{l}\text { Province } \\
\text { Location }\end{array}$ & $\begin{array}{c}\text { Capacity } \\
\text { (tonnes/yr)* }\end{array}$ & Battle River & Genesee & HR Milner & Keephills & Sheerness & Sundance \\
\hline British Columbia & & \multicolumn{6}{|c|}{ (\$/tonne) } \\
\hline Merritt & 90,000 & 57 & 51 & 43 & 49 & 53 & 48 \\
\hline Kelowna & 50,000 & 52 & 47 & 48 & 48 & 47 & 48 \\
\hline Kamloops & 35,000 & 52 & 46 & 38 & 44 & 48 & 43 \\
\hline Prince George & 400,000 & 47 & 42 & 34 & 40 & 57 & 39 \\
\hline Armstrong & 50,000 & 47 & 43 & 44 & 44 & 43 & 44 \\
\hline Burns Lake & 400,000 & 66 & 55 & 47 & 53 & 70 & 52 \\
\hline Strathnaver & 200,000 & 57 & 46 & 38 & 44 & 61 & 44 \\
\hline Quesnel & 90,000 & 60 & 48 & 40 & 46 & 63 & 45 \\
\hline Williams Lake & 150,000 & 63 & 52 & 44 & 50 & 64 & 49 \\
\hline Houston & 150,000 & 71 & 60 & 52 & 57 & 75 & 57 \\
\hline Vanderhoof & 140,000 & 59 & 48 & 40 & 45 & 63 & 44 \\
\hline Princeton & 90,000 & 62 & 56 & 48 & 54 & 58 & 53 \\
\hline Vanderhoof & 30,000 & 59 & 48 & 40 & 45 & 63 & 44 \\
\hline \multicolumn{8}{|l|}{ Alberta } \\
\hline Grande Cache & 25,000 & 35 & 24 & 10 & 22 & 43 & 21 \\
\hline La Crete & 60,000 & 51 & 46 & 39 & 45 & 58 & 43 \\
\hline Slave Lake & 60,000 & 25 & 17 & 29 & 16 & 32 & 16 \\
\hline Total Capacity & $2,020,000$ & & & & & & \\
\hline
\end{tabular}

* Biomass Wood Markets, 2013

Estimates of \$/tonne based on Super B-train grain truck, hauling a maximum of 44 tonnes 
Table 4: Optimal Generating Capacities, Various Scenarios

\begin{tabular}{|c|c|c|c|c|c|c|}
\hline Scenario & $\begin{array}{l}\text { Co-fire } \\
\text { (MW) }\end{array}$ & $\begin{array}{l}\text { Coal } \\
(\mathrm{MW})\end{array}$ & $\begin{array}{l}\mathrm{CCGT}^{\mathrm{a}} \\
(\mathrm{MW})\end{array}$ & $\begin{array}{l}\mathrm{OCGT}^{\mathrm{a}} \\
(\mathrm{MW})\end{array}$ & $\begin{array}{r}\text { Electricity Cost } \\
(\$ / \mathrm{MWh})\end{array}$ & $\begin{array}{r}\text { Wood Pellets } \\
\text { (tonnes) }\end{array}$ \\
\hline Initial & 0 & 5,795 & 4,164 & 1,500 & 21.70 & 0 \\
\hline \multicolumn{7}{|c|}{ 5\% Co-fire Rate } \\
\hline \multicolumn{7}{|c|}{ Carbon tax } \\
\hline$\$ 0$ & 0 & 5,795 & 4,164 & 1,500 & 21.70 & 0 \\
\hline$\$ 50$ & 0 & 5,795 & 4,164 & 739 & 59.07 & 0 \\
\hline$\$ 100$ & 0 & 590 & 7,165 & 1,500 & 122.20 & 0 \\
\hline$\$ 150$ & 0 & 929 & 7,090 & 1,500 & 139.68 & 0 \\
\hline$\$ 200$ & 0 & 359 & 7,265 & 1,500 & 161.09 & 0 \\
\hline \multicolumn{7}{|c|}{ Feed-in tariff } \\
\hline$\$ 0$ & 0 & 5,795 & 4,164 & 1,500 & 21.70 & 0 \\
\hline$\$ 30$ & 0 & 5,795 & 4,164 & 1,375 & 21.70 & 0 \\
\hline$\$ 60$ & 0 & 5,795 & 4,164 & 1,375 & 21.70 & 0 \\
\hline$\$ 90$ & 5,795 & 0 & 4,164 & 1,418 & 35.84 & 507,576 \\
\hline$\$ 120$ & 5,795 & 0 & 4,164 & 1,418 & 34.90 & 507,576 \\
\hline \multicolumn{7}{|c|}{ 15\% Co-fire Rate } \\
\hline \multicolumn{7}{|c|}{ Carbon tax } \\
\hline$\$ 0$ & 0 & 5,795 & 4,164 & 1,500 & 21.70 & 0 \\
\hline$\$ 50$ & 3,398 & 1,736 & 4,164 & 699 & 53.36 & 890,185 \\
\hline$\$ 100$ & 990 & 0 & 6,417 & 1,500 & 115.48 & 228,972 \\
\hline$\$ 150$ & 0 & 929 & 7,090 & 1,500 & 139.68 & 0 \\
\hline$\$ 200$ & 0 & 359 & 7,265 & 1,500 & 161.09 & 0 \\
\hline \multicolumn{7}{|c|}{ Feed-in tariff } \\
\hline$\$ 0$ & 0 & 5,795 & 4,164 & 1,500 & 21.70 & 0 \\
\hline$\$ 30$ & 95 & 5,700 & 4,164 & 1,375 & 22.15 & 25,000 \\
\hline$\$ 60$ & 5,795 & 0 & 4,164 & 1,418 & 34.32 & $1,522,842$ \\
\hline$\$ 90$ & 5,795 & 0 & 4,164 & 1,418 & 31.52 & $1,522,842$ \\
\hline$\$ 120$ & 5,795 & 0 & 4,164 & 1,418 & 28.71 & $1,522,842$ \\
\hline
\end{tabular}

${ }^{\mathrm{a}}$ CCGT and OCGT refer to base-load and peak-load natural gas facilities, respectively 
Table 5: Total Emissions and Abatement Costs under 5\% and 15\% Cofire Scenarios $^{\mathrm{a}}$

\begin{tabular}{|c|c|c|c|c|}
\hline \multirow{2}{*}{$\begin{array}{l}\text { Scenario } \\
\text { Policy }\end{array}$} & \multicolumn{2}{|l|}{ 5\% Co-fire } & \multicolumn{2}{|l|}{ 15\% Co-fire } \\
\hline & $\begin{array}{r}\text { Emissions } \\
\left(\mathrm{Mt} \mathrm{CO}_{2}\right)\end{array}$ & $\begin{array}{r}\text { Abatement Cost } \\
\left(\$ / \mathrm{tCO}_{2}\right)\end{array}$ & $\begin{array}{r}\text { Emissions } \\
\left(\mathrm{Mt} \mathrm{CO}_{2}\right)\end{array}$ & $\begin{array}{r}\text { Abatement Cost } \\
\left(\$ / \mathrm{tCO}_{2}\right)\end{array}$ \\
\hline \multicolumn{5}{|l|}{ Carbon tax } \\
\hline$\$ 0$ & 56.5 & n.a. & 56.5 & n.a. \\
\hline$\$ 50$ & 45.6 & 262.18 & 42.6 & 253.06 \\
\hline$\$ 100$ & 32.2 & 323.30 & 33.5 & 318.08 \\
\hline$\$ 150$ & 29.9 & 348.41 & 29.9 & 348.41 \\
\hline$\$ 200$ & 29.9 & 410.99 & 29.9 & 410.99 \\
\hline \multicolumn{5}{|c|}{ Feed-in tariff } \\
\hline$\$ 0$ & 56.5 & n.a. & 56.5 & n.a. \\
\hline$\$ 30$ & 56.5 & n.a. & 56.4 & 240.33 \\
\hline$\$ 60$ & 56.5 & n.a. & 49.8 & 287.48 \\
\hline$\$ 90$ & 54.3 & 715.74 & 49.8 & 321.48 \\
\hline$\$ 120$ & 54.3 & 749.39 & 49.8 & 355.37 \\
\hline
\end{tabular}

\footnotetext{
${ }^{a}$ n.a. refers to not applicable or negligible.
} 
Table 6: Age and Capacity of Coal-Fired Units in Alberta Units Affected by Canadian Regulations within First 10 Years of Implementation (2015-2025) Indicated in Bold

\begin{tabular}{ccccc}
\hline $\begin{array}{c}\text { Station } \\
\text { Unit }\end{array}$ & $\begin{array}{c}\text { Established } \\
\text { (Year) }\end{array}$ & $\begin{array}{c}\text { Capacity } \\
\text { (MW) }\end{array}$ & $\begin{array}{c}\text { Age in } \\
2015\end{array}$ & $\begin{array}{c}\text { Useful Years } \\
\text { Left by 2015 }\end{array}$ \\
\hline Battle River & & & & \\
$\mathbf{3}$ & $\mathbf{1 9 6 9}$ & $\mathbf{1 5 0}$ & $\mathbf{4 6}$ & $\mathbf{1}$ \\
$\mathbf{4}$ & $\mathbf{1 9 7 5}$ & $\mathbf{1 5 0}$ & $\mathbf{4 0}$ & $\mathbf{5}$ \\
5 & 1981 & 389 & 34 & 11 \\
Genesee & & & & \\
1 & 1989 & 410 & 26 & 19 \\
2 & 1994 & 410 & 21 & 24 \\
3 & 2005 & 495 & 10 & 35 \\
HR Milner & & & & \\
$\mathbf{1}$ & $\mathbf{1 9 7 2}$ & $\mathbf{1 5 8}$ & $\mathbf{4 3}$ & $\mathbf{2}$ \\
Keephills & & & & \\
1 & 1983 & 396 & 32 & 13 \\
2 & 1983 & 396 & 32 & 13 \\
3 & 2011 & 495 & 4 & 41 \\
Sheerness & & & & \\
1 & 1986 & 390 & 29 & 16 \\
2 & 1990 & 390 & 25 & 20 \\
Sundance & & & & \\
$\mathbf{3}$ & $\mathbf{1 9 7 6}$ & $\mathbf{4 0 8}$ & $\mathbf{3 9}$ & $\mathbf{6}$ \\
$\mathbf{4}$ & $\mathbf{1 9 7 7}$ & $\mathbf{3 8 6}$ & $\mathbf{3 8}$ & $\mathbf{7}$ \\
$\mathbf{5}$ & $\mathbf{1 9 7 8}$ & $\mathbf{3 8 6}$ & $\mathbf{3 7}$ & $\mathbf{8}$ \\
$\mathbf{6}$ & $\mathbf{1 9 8 0}$ & $\mathbf{3 8 6}$ & $\mathbf{3 5}$ & $\mathbf{1 0}$ \\
\hline
\end{tabular}


Table 7: Optimal Electrical Generating Assets for Meeting Coal-Fired Performance Standards in Alberta

\begin{tabular}{|c|c|c|c|c|c|c|c|c|}
\hline Scenario & $\begin{array}{r}\text { Co-fire } \\
(\mathrm{MW}) \\
\end{array}$ & $\begin{array}{r}\text { Coal } \\
(\mathrm{MW})\end{array}$ & $\begin{array}{l}\text { CCGT } \\
\text { (MW) }\end{array}$ & $\begin{array}{r}\text { OCGT } \\
(\mathrm{MW}) \\
\end{array}$ & $\begin{array}{r}\text { Electricity } \\
\text { Cost } \\
(\$ / M W h) \\
\end{array}$ & $\begin{array}{l}\text { Emissions } \\
\text { (Mt CO2) }\end{array}$ & $\begin{array}{r}\text { Abatement } \\
\text { Cost } \\
(\$ / \mathrm{tCO} 2) \\
\end{array}$ & $\begin{array}{r}\text { Pellets } \\
\text { (tonnes) } \\
\text { (\$/tCO2) } \\
\end{array}$ \\
\hline Initial & 0 & 5,795 & 4,164 & 1,500 & 21.70 & 56.54 & n.a. & n.a. \\
\hline No Co-fire & n.a. & 3,771 & 4,164 & 1,500 & 41.17 & 47.77 & 135.79 & n.a. \\
\hline \multicolumn{9}{|l|}{ Co-fire } \\
\hline Current & 495 & 3,771 & 4,164 & 1,500 & 36.84 & 47.45 & 169.92 & 484,998 \\
\hline \multicolumn{9}{|c|}{ Carbon tax } \\
\hline$\$ 50$ & 2,024 & 3,771 & 4,164 & 810 & 76.94 & 36.87 & 221.45 & $1,985,328$ \\
\hline$\$ 100$ & 2,024 & 599 & 3,196 & 1,500 & 108.88 & 30.66 & 265.50 & $1,985,328$ \\
\hline$\$ 150$ & 2,024 & 934 & 3,263 & 1,500 & 126.75 & 28.44 & 295.01 & $1,984,637$ \\
\hline$\$ 200$ & 2,024 & 357 & 3,087 & 1,500 & 147.18 & 28.34 & 351.51 & $1,984,107$ \\
\hline \multicolumn{9}{|c|}{ Feed-in-Tariff } \\
\hline$\$ 30$ & 2,024 & 3,771 & 4,164 & 1,375 & 49.21 & 47.61 & 250.90 & $1,985,616$ \\
\hline$\$ 60$ & 2,024 & 3,771 & 4,164 & 1,375 & 52.86 & 47.61 & 284.25 & $1,985,622$ \\
\hline$\$ 90$ & 2,024 & 3,771 & 4,164 & 1,375 & 56.39 & 47.61 & 316.38 & $1,986,007$ \\
\hline$\$ 120$ & 2,024 & 3,771 & 4,164 & 1,375 & 60.04 & 47.61 & 349.73 & $1,986,007$ \\
\hline
\end{tabular}


Table 8: Optimal Wood Pellet Shipments to Supply Alberta Co-fired Generators Subject to Performance Standards and Feed-in Tariff of \$50/MWh

\begin{tabular}{|c|c|c|c|c|c|c|c|}
\hline \multirow{3}{*}{$\begin{array}{l}\text { Pellet Producer } \\
\text { Prov. } \\
\text { Location } \\
\end{array}$} & \multicolumn{7}{|c|}{ Shipments to Coal-Fired Power Plant } \\
\hline & \multicolumn{2}{|c|}{ Battle River } & \multirow{2}{*}{$\begin{array}{c}\begin{array}{c}\text { HR } \\
\text { Milner }\end{array} \\
\text { Unit 1 }\end{array}$} & \multicolumn{4}{|c|}{ Sundance } \\
\hline & Unit 3 & Unit 4 & & Unit 3 & Unit 4 & Unit 5 & Unit 6 \\
\hline British Columbia & \multicolumn{7}{|c|}{ (tonnes) } \\
\hline Merritt & 0 & 0 & 0 & 0 & 0 & 0 & 90,000 \\
\hline Kelowna & 37,185 & 12,815 & 0 & 0 & 0 & 0 & 0 \\
\hline Kamloops & 0 & 0 & 0 & 13,468 & 21,532 & 0 & 0 \\
\hline Prince George & 0 & 134,370 & 0 & 265,630 & 0 & 0 & 0 \\
\hline Armstrong & 50,000 & 0 & 0 & 0 & 0 & 0 & 0 \\
\hline Burns Lake & 0 & 0 & 0 & 0 & 21,244 & 378,756 & 0 \\
\hline Strathnaver & 0 & 0 & 130,035 & 0 & 69,965 & 0 & 0 \\
\hline Quesnel & 0 & 0 & 0 & 0 & 0 & 0 & 90,000 \\
\hline Williams Lake & 0 & 0 & 0 & 91,244 & 0 & 0 & 58,756 \\
\hline Houston & 0 & 0 & 0 & 0 & 116,014 & 0 & 0 \\
\hline Vanderhoof & 0 & 0 & 0 & 0 & 0 & 0 & 140,000 \\
\hline Princeton & 0 & 0 & 0 & 0 & 90,000 & 0 & 0 \\
\hline Vanderhoof & 0 & 0 & 0 & 30,000 & 0 & 0 & 0 \\
\hline \multicolumn{8}{|l|}{ Alberta } \\
\hline Grande Cache & 0 & 0 & 25,000 & 0 & 0 & 0 & 0 \\
\hline La Crete & 60,000 & 0 & 0 & 0 & 0 & 0 & 0 \\
\hline Slave Lake & 0 & 0 & 0 & 0 & 60,000 & 0 & 0 \\
\hline Total Capacity & 147,185 & 147,185 & 155,035 & 400,343 & 378,756 & 378,756 & 378,756 \\
\hline
\end{tabular}

${ }^{\mathrm{a}}$ Biomass Wood Markets, 2013

Estimates of \$/tonne based on Super B-train grain truck, hauling a maximum of 44 tonnes 